\title{
KONDISI TERUMBU KARANG DI TANJUNG GOSONGSENG DESA KAHYAPU PULAU ENGGANO PROVINSI BENGKULU
}

\author{
Oleh \\ Muhammad Andre Nugraha, Dewi Purnama*, Mukti Dono Wilopo dan Yar Johan \\ Program Studi Ilmu Kelautan Fakultas Pertanian Universitas Bengkulu, Bengkulu \\ Email:de marine@yahoo.co.in \\ Received February 2016, Accepted March 2016
}

\begin{abstract}
ABSTRAK
Penelitian ini bertujuan untuk menganalisis kondisi terumbu karang dan mengevaluasi kondisi terumbu karang berdasarkan nilai indeks keanekaragaman, indeks keseragaman, indeks dominansi dan indeks mortalitas. Metode yang digunakan adalah metode suvei dengan menggunakan transek garis menyinggung (LIT), terdiri atas 3 stasiun dimana masing-masing stasiun dibagi atas 2 sub kedalaman yakni pada kedalaman $3 \mathrm{~m}$ dan $10 \mathrm{~m}$. Tipe terumbu karang yang ada di Perairan Tanjung Gosongseng Pulau Enggano memiliki tipe terumbu karang tepi. Hasil penelitian ditemukan 11 jenis bentuk pertumbuhan, yaitu Acropora Branching (ACB), Acropora Digitate (ACD), Acropora Encrusting (ACE), Acropora Submassive (ACS), Acropora Tabulate (ACT), Coral Branching (CB), Coral Massive (CM), Coral Encrusting (CE), Coral Submassive (CS), Coral Foliose (CF), dan Coral Mushroom (CMR). Tutupan karang di Tanjung Gosongseng menurut Kep Men LH no 4 Tahun 2001 tergolong buruk, sedang, baik dan, baik sekali keanekaragaman di kategorikan sedang, dominansi dikategorikan rendah, keseragaman di kategorikan tinggi, serta mortalitas sedang. Untuk parameter kualitas air baik untuk pertumbuhan terumbu karang.
\end{abstract}

Kata Kunci : Tanjung gosongseng, terumbu karang, acropora, LIT, persentase tutupan 


\section{PENDAHULUAN}

Secara geografis, Pulau Enggano berada di wilayah Samudera Indonesia yang posisi astronomisnya terletak antara $102,05^{\circ}-102,25^{\circ}$ Bujur Timur dan $5,17^{\circ}-5,31^{\circ}$ Lintang Selatan. Kecamatan Pulau Enggano mempunyai luas daratan $\pm 40,060$ Ha yang terdiri dari 6 Desa (Senoaji $d k k ., 2006$ ).

Desa Kahyapu yang memiliki fasilitas dermaga penyebrangan kapal Ferry, berdasarkan survey pendahuluan yang dilakukan peneliti, Desa Kahyapu belum memiliki Peraturan Desa mengenai ekosistem terumbukarang, namun sudah memiliki peraturan tentang pemanfaatan karang yang telah mati untuk keperluan masyarakat seperti membangun jalan pengganti matrial batu, lokasi pengambilan karang mati tersebut telah di tentukan, yang berada di wilayah Sawang Bengkok, selain itu Desa Kahyapu memiliki bentang alam areal Tanjung yang menjorok kelaut sehingga masyarakat memanfaatkanya sebagai daerah penangkapan ikan, aktifitas penangkapan yang dilakukan di Tanjung Gosongseng tidak menutup kemungkinan terjadinya kerusakan ekosistem terumbu karang karena aktifitas tersebut yang melibatkan alat tangkap dari yang diperbolehkan hingga yang dilarang, sebagian besar wilayah Tanjung Gosongseng mengalami kerusakan akibat alat tangkap yang menggunakan bahan peledak seperti bom ikan yang sebelumnya sering di gunakan nelayan. Oleh karena itu, penelitian ini untuk mengetahui kondisi terumbu karang di Tanjung Gosongseng.

\section{Waktu dan Lokasi Penelitian.}

\section{METODOLOGI PENELITIAN}

Penelitian ini di laksanakan pada bulan Mei sampai degan Desember 2014 lokasi pengambilan data di Tanjung Gososngseng Desa Kahyapu Pulau Enggano Provinsi Bengkulu. (Gambar 1)

\section{Alat dan Bahan Penelitian} Tabel 1.

Alat dan bahan yang digunakan dalam penelitian ini, dapat dilihat pada

Tabel 1 : Alat dan Bahan Penelitian

\begin{tabular}{ccl}
\hline No & Nama Jenis & \multicolumn{1}{c}{ Fungsi } \\
\hline 1 & Alat SCUBA diving & Untuk penyelaman \\
\hline 2 & GPS & Untuk menentukan lokasi \\
\hline 3 & Roll meter & Mengukur panjang koloni karang \\
\hline 4 & Kamera bawah air & Mendokumentasikan terumbu karang \\
\hline 5 & Buku identifikasi & Untuk mengidentifikasi koloni karang \\
\hline 6 & Perahu & Tranportasi menuju lokasi pengambilan data \\
\hline 7 & Snorkel set & Untuk pengambilan data \\
\hline 8 & Terumbu karang & Objek penelitian \\
\hline
\end{tabular}

\section{Prosedur Penelitian \\ Penentuan Stasiun Penelitian}

Penelitian ini dilakukan dengan Penggunaan metode transek garis. Transek garis di gunakan untuk menggambarkan struktur komunitas karang dengan melihat kondisi terumbu karang. Garis transek menggunakan roll meter, di mulai dari kedalaman dimana masih ditemukan terumbukarang batu (25m) sampai di daerah pantai mengikuti pola kedalaman garis kontur. Penelitian dilakukan pada 3 stasiun, dimana dalam setiap stasiun terdapat 2 titik kedalaman 
yaitu $3 \mathrm{~m}$ dan $10 \mathrm{~m}$. Panjang transek yang di gunakan adalah $50 \mathrm{~m}$ yang penempatannya sejajar dengan garis pantai pulau. Kamera digunakan untuk pengambilan gambaran terumbu karang agar diperoleh ketelitian yang lebih tinggi. Dalam menentukan titik stasiun pengamatan ditentukan menggunakan GPS. (Tabel 2).

Tabel 2. Titik koordinat pengamatan pengambilan data

\begin{tabular}{ccc}
\hline Stasiun & Bujur Timur & Lintang Selatan \\
\hline 1 & $102^{\circ} 24^{\prime} 770^{\prime \prime}$ & $05^{\circ} 24^{\prime} 283$ \\
\hline 2 & $102^{\circ} 24^{\prime} 064^{\prime \prime}$ & $05^{\circ} 24^{\prime} 736$ \\
\hline 3 & $102^{\circ} 23^{\prime} 298^{\prime \prime}$ & $05^{\circ} 28^{\prime} 474$ \\
\hline
\end{tabular}

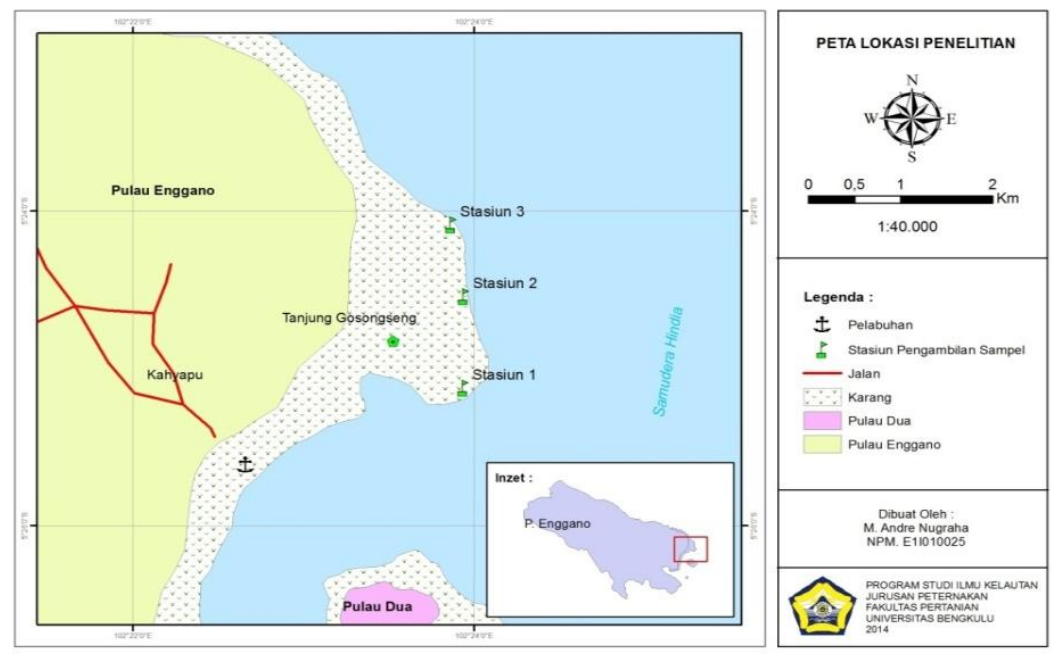

Gambar 1 . Peta lokasi penelitian Tanjung Gosongseng. (Data primer, 2014).

Pengukuran dilakukan dengan tingkat ketelitian mendekati sentimeter. Dalam penelitian ini satu koloni dianggap satu individu. Jika satu koloni dari jenis yang sama dipisahkan oleh satu atau beberapa bagian yang hidup maka tiap bagian yang mati di anggap sebagi satu individu tersendiri. Panjang tumpang tindih koloni dicatat yang nantinya akan digunakan untuk menganalisa kehadiran karang mati lepas atau masif (UNEP, 1993).

\section{Pengambilan Data}

Pengambilan sampel karang dalam penelitian ini menggunakan metode transek garis mengacu pada English et al. (1997). (Gambar 2).

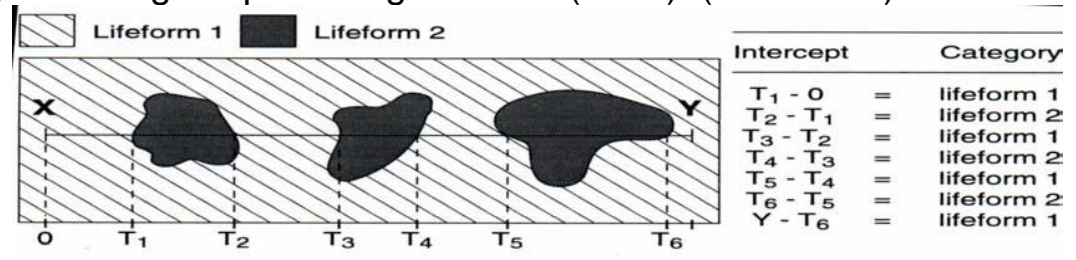

\begin{tabular}{cc|c}
\multicolumn{2}{c|}{ Intercept } & Category \\
\hline$T_{1}-0$ & $I_{1}$ & lifeform 1 \\
$T_{2}-T_{1}$ & $I_{2}$ & lifeform 2 \\
$T_{3}-T_{2}$ & $I_{3}$ & lifeform 1 \\
$T_{4}-T_{3}$ & $I_{4}$ & lifeform 2 \\
$T_{5}-T_{4}$ & $I_{5}$ & lifeform 1 \\
$T_{6}-T_{5}$ & $I_{6}$ & lifeform 2 \\
$Y-T_{6}$ & $I_{7}$ & lifeform 1
\end{tabular}

Gambar 2. Cara Pencatatan Data Koloni Karang pada Metode Transek Garis (UNEP, 1993). 


\section{Parameter Kualitas Air}

Pengambilan data parameter kualitas air di setiap stasiun pengamatan meliputi alat yang di gunakan dapat dilihat pada Tabel 4.

Tabel 4. Parameter kualitas air.

\begin{tabular}{cccc}
\hline No & Paremeter & Satuan & Alat dan Bahan \\
\hline 1 & Kecerahan & Meter & Secchi disc \\
2 & Kedalaman & Meter & Tali pengukur dan konsul \\
3 & Kecepatan Arus & $\mathrm{cm} / \mathrm{dtk}$ & Flow meter \\
4 & Salinitas & $(\% \circ)$ & Handrefractometer \\
5 & $\mathrm{pH}$ & - & pH meter \\
6 & Suhu & ${ }^{0} \mathrm{C}$ & Termometer \\
\hline
\end{tabular}

Pengukuran salinitas dilakukan dengan menggunakan Handrefractometer. Cara kerja pengukuran yaitu Handrefractometer terlebih dahulu dikalibrasi dengan Aquades hingga garis biru yang tampak pada lensa okuler tepat pada posisi $0 \%$ lalu sampel air diteteskan pada permukaan kaca pada Handrefractometer, Handrefraktometer dihadapkan kearah cahaya, dan amati dari lensa okuler kemudian nilai salinitas ditunjuk kan oleh garis biru horizontal memiliki nilai dalam satuan permil.

Suhu yang diukur adalah suhu permukaan perairan pengukuran suhu dilakukan dengan menggunakan Termometer air raksa, Termometer dicelupkan pada badan air yang diteliti, lalu Termometer didiamkan selama kurang lebih 1-2 menit sampai angka yang ditunjukkan konstan atau tidak berubah.

Kecerahan diukur dengan menggunakan secchidisc, yang ditenggelamkan pada badan air yang diteliti dengan Kedalaman awal mula Secchidisk hilang dari pandangan dicatat sebagai L1, lalu Secchidisc ditarik keatas dan dicatat sebagai L2 pada saat secchidisc tersebut mulai tampak, dan kemudian kecerahan perairan adalah hasil penjumlahan $(\mathrm{L} 1+\mathrm{L} 2: 2)$.

Pengukuran arus dilakukan dengan menggunakan flowmeter,yang kemudian, dimasukkan ke dalam air laut, lalu tunggu sampai angka tertera atau muncul pada layar flow meter.

Pengukuran $\mathrm{pH}$ perairan menggunakan $\mathrm{pH}$ meter, yaitu dengan cara mencelupkan alat kemudian mencatat hasil pengukuran yang di hasilkan.

\section{Persentase Tutupan Karang}

\section{Analisis Data}

Data yang telah dikumpulkan, dianalisis menggunakan program Microsoft Excel untuk kemudian dibahas secara deskriptif. Kondisi terumbu karang diduga melalui pendekatan persentase tutupan karang dengan kategori kondisi dari English et al. (1997).

Keterangan :

$$
\mathrm{L}=\frac{L i}{n} \times 100 \%
$$

$\mathrm{L}=$ Persentase tutupan karang (\%)

$\mathrm{Li}=$ Panjang lifeform jenis ke-i

$\mathrm{N}=$ Panjang transek $50(\mathrm{~cm})$

Klasifikasi kondisi terumbu karang berdasarkan persentase penutupannya, menurut Keputusan MENLH No 4 tahun 2001 dapat dilihat pada Tabel 5. 
Tabel 5. Baku kerusakan terumbu karang.

\begin{tabular}{|c|c|c|c|}
\hline Parameter & \multicolumn{3}{|c|}{ Kriteria Baku Kerusakan Terumbu Karang (dalam \%) } \\
\hline \multirow{4}{*}{$\begin{array}{c}\text { Persentase } \\
\text { Luasan Tutupan } \\
\text { Terumbu yang } \\
\text { Hidup }\end{array}$} & \multirow{2}{*}{ Rusak } & Buruk & $0-24,9$ \\
\hline & & Sedang & $25-49,9$ \\
\hline & \multirow{2}{*}{ Baik } & Baik & $50-74,9$ \\
\hline & & Baik Sekali & $75-100$ \\
\hline
\end{tabular}

\section{Indeks Keanekaragaman (H')}

Nilai indeks keanekaragaman $\left(\mathrm{H}^{\prime}\right)$ berdasarkan presentase penutupan biota karang digunakan untuk memperoleh gambaran keadaan populasi organisme secara matematis untuk mempermudah dalam melakukan analisa informasi-informasi mengenai jumlah bentuk pertumbuhan biota karang dalam suatu komunitas. (Shannon and Wiener, 1949 in Krebs, 1972)

Dimana :

$$
H^{\prime}=-\sum_{i=1}^{\mathrm{S}} p i \log _{2} p \mathrm{i}
$$

$\mathrm{H}^{\prime}=$ Indeks keanekaragaman

$\mathrm{Pi}=$ Perbandingan proporsi bentuk pertumbuhan ke $\mathrm{i}$

$S=$ Jumlah kategori bentuk pertumbuhan karang

Selanjutnya nilai indeks keanekaragaman digolongkan dalam kriteria sebagai berikut:

Log $2 \mathrm{Pi}:$ 3, $321928 \log \mathrm{pi}$

$H^{\prime}<1 \quad:$ Keanekaragaman kecil

$H^{\prime}=1-3:$ Keanekaragaman sedang

$\mathrm{H}^{\prime}>3$ : Keanekaragaman tinggi

\section{Indeks Keseragaman (E)}

Nilai persentase penutupan biota karang digunakan untuk membandingkan nilai indeks keanekaragaman dengan nilai keanekaragaman maksimum yang teramati, sehingga dapat digunakan sebagai indikator dalam menentukan dominansi dari biota bentuk pertumbuhan karang (Krebs, 1985).

Dimana:

$$
E=\frac{H^{\prime}}{H_{m a k s}}
$$

$$
\begin{array}{ll}
E & =\text { indeks keseragaman } \\
H^{\prime} \text { mak } & =\text { Log2 } \mathrm{S} \\
\mathrm{H}^{\prime} & =\text { Keseimbangan spesies } \\
S & =\text { Jumlah kategori bentuk pertumbuhan karang }
\end{array}
$$

Nilai indeks keseragaman berkisar antara 0-1. Kriteria nilai indeks keseragaman berdasarkan kriteria adalah sebagai berikut :

$$
\begin{aligned}
& \mathrm{E}<0,4 \quad=\text { Keseragaman populasi kecil } \\
& \mathrm{E}=0,4-0,6=\text { Keseragaman populasi sedang } \\
& \mathrm{E}>0,6 \quad=\text { Keseragaman populasi tinggi }
\end{aligned}
$$

\section{Indeks Dominansi (C)}

Indeks dominansi berdasarkan persentase penutupan bentuk pertumbuhan karang digunakan untuk melihat tingkat dominansi kelompok biota tertentu (Simpson, 1949 in Odum, 1971) yaitu : 
Dimana :

$$
C=\sum_{i=l}^{S}(P i)^{2}
$$

$\mathrm{C}=$ indeks dominansi

$\mathrm{Pi}=$ Proporsi jumlah kategori bentuk pertumbuhan karang ke $\mathrm{i}$

$S$ = Jumlah bentuk pertumbuhan karang

Nilai indeks dominansi berkisar antara $0-1$. Semakin tinggi nilai indeks tersebut, maka akan terlihat suatu biota mendominasi. Jika nilai indeks dominansi (C) mendekati nol, maka hal ini menunjukkan pada perairan tersebut tidak ada biota yang mendominasi dan biasanya diikuti oleh nilai keseragaman (E) yang tinggi. Sebaliknya, jika nilai indeks dominansi (C) mendekati satu, maka hal ini menggambarkan pada perairan tersebut ada salah satu biota yang mendominasi dan biasanya diikuti oleh nilai keseragaman yang rendah. Adapun Kriteria nilai indeks dominansi adalah sebagai berikut :

$\mathrm{C}=0-0.5 \quad$ : Dominansi rendah

$C>0,5-0.75$ : Dominansi sedang

$\mathrm{C}>0,75-1$ : Dominansi tinggi

\section{Indeks Mortalitas Karang (IM)}

Indeks mortalitas digunakan untuk menduga tingkat kesehatan atau kondisi dari terumbu karang. Indeks ini memperlihatkan besarnya perubahan karang hidup menjadi mati. Nilai indeks mortalitas yang mendekati 0,0 menunjukkan bahwa tidak ada perubahan yang berarti bagi karang hidup yang mati, atau kondisi ini memiliki tingkat kesehatan yang tinggi. Sedangkan nilai yang mendekati 1,0 menunjukkan bahwa terjadi perubahan yang berarti dari karang hidup menjadikarang mati, atau memiliki tingkat kesehatan karang yang rendah. Nilai indeks mortalitas karang didapatkan dari persentase penutupan karang mati dan persentase tutupan karang hidup (Gomez, 1994 in Edinger et al., 1998):

Keterangan :

$$
\mathrm{MI}=\frac{\% D C}{\% D C+\% C C}
$$

$\mathrm{MI}=$ Indeks Kematian

$D C=$ Persentase Karang Mati

$C C=$ Persentase Karang Hidup

\section{Indeks kesamaan}

Indeks kesamaan digunakan untuk menentukan pola pengelompokan habitat berdasarkan analisis kluster (cluster analysis) yang menggunakan data persen penutupan substrat dasar. Data komposisi habitat (parameter biologis) yang digunakan untuk pengelompokan karang tersebut adalah nilai karang hidup, karang mati, pasir, alga dan hewan bentik lainnya (Dartnal and Jones, 1986). Berdasrkan indeks kesamaan Sorensen's Coefficient. Indeks yang diolah menggunakan program MVSP versi 3 (Multi Variate Statistical Package) berikut indeks Sorensen (1948) dalam Krebs (2014).

$$
s_{S} \frac{2 a}{2 a+b+c} \times 100
$$

Keterangan : Ss = indeks kesamaan sorensen

$a=$ jumlah contoh dimana terdapat spesies $A$ dan $B$

$b=$ jumlah contoh dimana terdapat spesies $A$ 


$$
\text { C = jumlah contoh dimana terdapat spesies B }
$$

Dengan kriteria nilai indeks kesamaan Sorensen Dengan kriteria keputusan: dua

stasiun tidak berbeda jika nilai Ss $>50$. Kumpulan indek kesamaan Sorensen yang kemudian digunakan untuk membuat dendogram berdasarkan metode keterkaitan rata-rata antar kelompok.

\section{HASIL DAN PEMBAHASAN}

\section{Gambaran Umum Lokasi Penelitian dan Terumbu Karang}

Komponen penyusun ekosistem terumbu karang di Tanjung Gosongseng ini terdiri dari komponen biotik (hidup), dan abiotik. Daerah ini pada setiap harinya dimanfaatkan sebagai daerah lokasi mencari ikan oleh seluruh masyarakat Pulau Enggano dan bahkan pemancing dari luar Pulau Enggano, mulai dari menjaring sampai dengan menggunakan tembak. Selain itu di daerah tersebut seringkali dipenuhi oleh sampah yang terapung dari laut lepas yang di bawa oleh air pasang dan arus yang mengakibatkan banyaknya tumpukan sampah berada di pinggir selain itu di lokasi tersebut pada bulan dan musim tertentu memiliki pecahan ombak yang besar. Menurut Westmacott et al. (2000), selain faktor alam, kerusakan terumbu karang sebagian besar disebabkan oleh kegiatan manusia yang merusak terumbu karang itu sendiri.

\section{Kategori Karang}

Kehadiran jenis karang batu di suatu lokasi tergantung pada kondisi perairan setempat seperti cahaya matahari, salinitas, temperatur, pergerakan arus, substrat dan kecerahan air (Wells, 1956), Substrat merupakan salah satu faktor penting dalam menunjang kehadiran karang batu di suatu perairan. Substrat yang keras dan bersih dari lumpur diperlukan untuk pelekatan larva planula karang batu yang akan membentuk koloni baru. Keberadaan karang batu di perairan Tanjung Gosongseng secara umum dipengaruhi oleh substrat dasar yang berupa karang mati beralgae (DCA) yang menyebar di seluruh lokasi dan patahan karang $(R)$ yang merupakan komponen abiotik yang mempunyai nilai persentase tertinggi di bandingkan dengan pasir (S), pengkategorian terumbu karang di setiap setasiun pengamatan memiliki bentuk yang beranekaragam, dengan jumlah masing-masing pada setiap stasiun tidak jauh berbeda, pada kedalaman $3 \mathrm{~m}$ secara keseluruhan banyaknya pertumbuhan tidak jauh berbeda pada setiap stasiunnya, dan di kedalaman $10 \mathrm{~m}$ memiliki kesamaan jumlah jenis pertumbuhan yang hampir sama di setiap stasiunnya. Dari beragamnya jenis kategori yang di temukan di setiap setasiun pengamatan dan kedalaman terdapat jenis kategori yang mendominasi yaitu jenis karang batu non-acropora dan jenis lifeform yang sering di temukan adalah coral encrusting dan diikuti coral foliose sedangkan kategori acropora yaitu branching dan digitate. Dikarnakan lokasi penelitian memiliki kecerahan yang baik, pola arus dan ombak yang cukup kuat. Pertumbuhan karang batu ditempat yang airnya teraduk oleh angin, arus dan ombak lebih baik daripada perairan yang tenang dan terlindung (Sukarno dkk.,1981). Sedangkan karang kategori mushroom (CMR) dan diikuti oleh coral submassive (CM) merupakan jenis yang paling sedikit di temukan dari jenis yang lainnya. 


\section{Klaster Hubungan kemiripan Rata-Rata Antar Lokasi}

Analisis klaster dilakukan untuk mencari kemiripan antara stasiun beserta substasiunnya. Menurut Krebs (1985) indeks similaritas digunakan untuk mengetahui seberapa besar kesamaan organisme yang hidup di dua tempat yang berbeda. Hasil cluster analysis menggunakan aplikasi MVSP berdasarkan matriks similarity Sorensen's Coefficient. Secara visual hasil pengelompokan dapat dilihat pada Gambar 3.

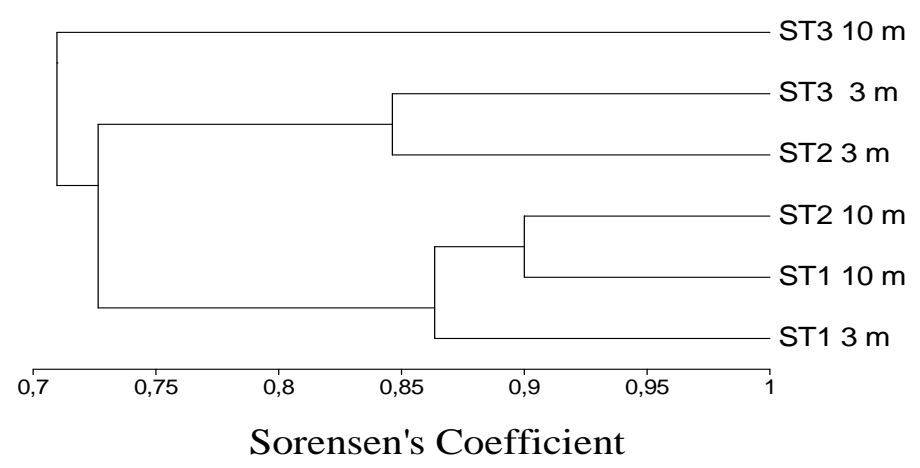

Gambar 3. Dendogram analisis klaster (Cluster Analisys) pada tiap Lokasi.

Hasil analisis dari gambar dendogram menunjukan bahwa terdapat lima pengelompokan besar. Dari kelima kelompok tersebut kelompok 1 yang memiliki tingkatan kemiripan paling besar pada stasiun 1 dengan substasiun $10 \mathrm{~m}$, stasiun 2 substasiun $10 \mathrm{~m}$ dengan kemiripan 90 sesuai dengan kriteria keputusan yaitu dua stasiun tidak berbeda jika nilai Ss (indeks Sorensen) $>50$. Secara umum kesemua kelompok memiliki kesamaan komunitas biota karang dan fauna karang antar stasiun penelitian.

\section{Komposisi Substrat Bentik}

Tabel 6. Persentase tutupan komponen abiotik dan biotik

\begin{tabular}{|c|c|c|c|c|c|c|c|}
\hline \multirow{4}{*}{ Komponer } & & \multicolumn{6}{|c|}{ Persentase Tutupan (\%) } \\
\hline & & \multicolumn{6}{|c|}{ Stasiun } \\
\hline & & \multicolumn{2}{|c|}{1} & \multicolumn{2}{|c|}{2} & \multicolumn{2}{|c|}{3} \\
\hline & & $3 \mathrm{~m}$ & $10 \mathrm{~m}$ & $3 \mathrm{~m}$ & $10 \mathrm{~m}$ & $3 \mathrm{~m}$ & $10 \mathrm{~m}$ \\
\hline \multirow{4}{*}{ Biotik } & Acrcopora & 27,64 & 17,60 & 39,58 & 29,7 & 4,76 & 1,54 \\
\hline & Non Acrcopora & 47,18 & 3,24 & 42,9 & 21,3 & 31,28 & 9,92 \\
\hline & Bioata Lain & 2,56 & 0 & 5,16 & 0 & 1,26 & 9,38 \\
\hline & Jumlah & 77,38 & 20,84 & 87,64 & 51 & 37,3 & 20,84 \\
\hline \multirow{7}{*}{ Abiotik } & Karang Mati & 13,3 & 79,16 & 6,98 & 40,12 & 11,58 & 2,26 \\
\hline & Pasir & 0 & 0 & 3,72 & 0 & 0,6 & 0 \\
\hline & $\mathrm{R}$ & 9,32 & 0 & 1,66 & 8,88 & 50,52 & 76,9 \\
\hline & WA & 0 & 0 & 0 & 0 & 0 & 0 \\
\hline & RCK & 0 & 0 & 0 & 0 & 0 & 0 \\
\hline & Jumlah & 22,62 & 79,16 & 12,36 & 49 & 62,7 & 79,16 \\
\hline & umlah Total & 100 & 100 & 100 & 100 & 100 & 100 \\
\hline
\end{tabular}

Sumber. Data primer, 2014

Secara keseluruhan stasiun dan kedalaman komponen biotik memiliki jumlah persentase tutupan yang besar dari komponen abiotik dikarnakan pada 
komponen biotik persen tutupan mencapai 87,64. Sedangkan komponen abiotik sebesar $79,16 \%$. Dugaan karana lokasi tanjung gosongseng memiliki sirkulasi air laut yang lebih baik yangmana lokasi ini langsung berhadapan dengan wilayah samudra, di banding daerah yang tertutup atau perairan yang tidak memiliki sirkulasi air yang baik seperti pada daerah Pulau Dua dan Pulau Merbau yang menghadap ke arah Pulau Enggano.

\section{Persentase Tutupan Karang Hidup}

Persentase tutupan karang hidup terdiri dari substrat bentik.

Tabel 7. Persentase tutupan karang hidup

\begin{tabular}{ccccc}
\hline \multirow{2}{*}{ Stasiun } & \multicolumn{5}{c}{ Kedalaman } \\
\cline { 2 - 5 } & (\%) Tutupan & Kategori & (\%) Tutupan & Kategori \\
\cline { 2 - 5 } & 74,82 & Baik & 20,84 & Buruk \\
\hline II & 82,48 & Baik Sekali & 51 & Baik \\
\hline III & 36,04 & Sedang & 11,46 & Buruk \\
\hline
\end{tabular}

Sumber. Data Primer, 2014

Suatu ekosistem terumbu karang akan semakin bagus kondisinya apabila persentase penutupan karang hidup pada ekosistem tersebut lebih besar daripada persentase tutupan abiotiknya. Kriteria baku kerusakan terumbu karang, menurut KEPMENLH No 4. (2001).

Hasil penelitian menunjukkan bahwa tutupan terumbu karang memiliki kategori kondisi beragam. Persentase tutupan karang hidup tertinggi terdapat pada stasiun II dengan tutupan mencapai $82,48 \%$ yang berarti tutupan karang hidup pada stasiun ini termasuk pada kategori baik sekali. Menurut Sukarno (1994) persentase penutupan karang yang berkisar antara $75-100 \%$ termasuk dalam kondisi Baik Sekali. Hal ini diduga pada stasiun II kedalaman 3m memiliki jumlah persentase tutupan komunitas karang yang paling besar dengan nilai $87,64 \%$. Persentase tutupan karang terendah terdapat pada stasiun III dengan persentase tutupan $36,04 \%$ persentase tutupan masuk kedalam kategori tutupan karang sedang, pada stasiun I persentase tutupan karang sebesar $74,82 \%$, kategori tutupan baik.

Secara keseluruhan kondisi di stasiun II lebih bagus atau paling baik kondisinya dari pada stasiun I dan III, kondisi di stasiun II dikarnakan memiliki komponen penyusun biotik dan tutupan komunitas karang yang baik dengan banyaknya bentuk pertumbuhan komunitas terumbu karang di daerah tersebut. Sedangkan di stasiun pengamatan I dan III memiliki komponen abiotik terbesar terutama pada kedalaman $10 \mathrm{~m}$. diduga lokasi di stasiun II merupakan daerah yang berada di tengah tanjung sehingga arus yang berasal dari Samudra Hindi langsung menuju stasiun II, sedangkan dua stasiun yang lain berada di bagian sisi tanjung yang tidak memiliki potensi arus sebesar di stasiun II yang mana arus sangat berperan penting bagi binatang karang. Lalu di kedalaman $3 \mathrm{~m}$ secara keseluruhan memiliki nilai persentase yang bagus dari kedalaman $10 \mathrm{~m}$, di duga lokasi $3 \mathrm{~m}$ sangat bagus keadaan lingkungannya karena lokasi ini dekat dengan gelombang pecah yang cukup besar dan sedikit gangguan baik dari faktor manusia dan alam sedangkan di kedalaman $10 \mathrm{~m}$ relatif lebih banyak memiliki gangguan baik dari faktor alam dan manusia. 


\section{Persentase Tutupan Karang Mati}

Persentase tutupan karang mati terdiri atas jumlah keseluruhan karang mati (DC), karang mati dengan alga (DCA) dan Rubble (R) atau patahan karang. Persentase tutupan karang mati pada daerah pengamatan dengan kedalaman $3 \mathrm{~m}$ adalah 8,46 sampai dengan $62,1 \%$. Persentase tutupan karang mati tertinggi terdapat pada stasiun III dengan persentase tutupan $62,1 \%$. Persentase tutupan karang mati terendah terdapat pada stasiun II dengan persentase tutupan karang mati 8,46\% (Tabel 8).

Tabel 8. Persentase tutupan karang mati

\begin{tabular}{|c|c|c|c|c|c|c|c|}
\hline \multirow{4}{*}{ Kategori } & & \multicolumn{6}{|c|}{ Persentase Tutupan (\%) } \\
\hline & & \multicolumn{6}{|c|}{ Stasiun } \\
\hline & & \multicolumn{2}{|c|}{1} & \multicolumn{2}{|c|}{2} & \multicolumn{2}{|c|}{3} \\
\hline & Kedalaman & $3 \mathrm{~m}$ & $10 \mathrm{~m}$ & $3 \mathrm{~m}$ & $10 \mathrm{~m}$ & $3 \mathrm{~m}$ & $10 \mathrm{~m}$ \\
\hline DC & & 2,48 & 38,84 & 1,78 & 10,42 & 0 & 0 \\
\hline DCA & & 10,82 & 40,32 & 5,02 & 29,07 & 11,58 & 2,26 \\
\hline $\mathrm{R}$ & & 9,32 & 0 & 1,66 & 8,88 & 50,52 & 76,09 \\
\hline Jumlah & & 22,62 & 79,16 & 8,46 & 48,37 & 62,1 & 78,35 \\
\hline
\end{tabular}

Sumber. Data Primer, 2014

Persentase tutupan karang mati di perairan Tanjung Gosongseng, baik kedalaman $3 \mathrm{~m}$ maupun $10 \mathrm{~m}$ memiliki tutupan karang mati $13,3 \%$ dan $79,16 \%$. Jumlah persentase tutupan karang mati tertinggi pada stasiun 1 sebesar $79,16 \%$. $\mathrm{Hal}$ ini diduga karena rusaknya terumbu karang oleh beberapa faktor baik faktor alam dan lingkungan, menurut Dahuri (2003), penggunaan bahan peledak, bahan beracun dan pukat harimau berpotensi menimbulkan kerusakan yang luas terhadap ekosistem terumbu karang karena terumbu karang merupakan ekosistem yang sangat rentan terhadap gangguan dari kegiatan manusia dan pemulihannya memerlukan waktu yang lama.

Dalam usaha penangkapan ikan menggunakan alat tangkap yang tidak ramah lingkungan seperti bom, hal ini dilakukan karena kegiatan tersebut dianggap oleh sebagian masyarakat sangat efektif dan tidak tergantung pada musim. Selain itu, waktu yang diperlukan untuk melakukan kegiatan ini relatif lebih singkat dibandingkan dengan kegiatan penangkapan ikan dengan menggunakan peralatan lainnya seperti jaring, pancing dan sebagainya. Efek lain dari aktifistas tersebut adalah pada jangkar kapal yang di turunkan untuk menahan kapal yang selalu bergerak karena gelombang dan arus sehingga jangkar tersebut secara langsung tertarik dan menyapu karang yang ada di sekitarnya. Dugaan tersebut dapat di ikuti oleh banyaknya patahan karang berukuran kecil dan sangat berserakan dan hampir terdapat di stiap stasiun, terutama pada stasiun III yang memiliki jumlah patahan karang terbesar yang mencapai $76,90 \%$ diikuti stasiun II dan yang terakhir di stasiun I.

Menurut Burke et al. (2002) bahwa Terdapat beberapa penyebab kerusakan terumbu karang yaitu : (1) Aktivitas di laut antara lain dari kapal dan pelabuhan termasuk akibat langsung dari pelemparan jangkar kapal (2) Penangkapan ikan dengan menggunakan racun dan bom. (3) Perubahan iklim global. Hasil penelitian Suharsono (1995) luas terumbu karang Indonesia berada pada kondisi miskin yaitu mencapai $43 \%$. 


\section{Parameter Kualitas Air}

Karang sangat sensitif terhadap perubahan lingkungan perairan, terutama suhu, salinitas, sedimentasi dan eutrofikasi serta memerlukan kualitas perairan alami (Wallace, 1998). Nilai rata-rata dari hasil pengukuran parameter kualitas perairan yang dilakukan pada setiap stasiun pengamatan dan di masing-masing titik kedalamannya akan disajikan pada Tabel 9.

Tabel 9. Nilai parameter kualitas air

\begin{tabular}{lcccccc}
\hline & \multicolumn{6}{c}{ Stasiun Pengamatan } \\
\cline { 2 - 7 } Parameter Kualitas Air & \multicolumn{7}{c}{1} & \multicolumn{2}{c}{2} \\
\cline { 2 - 7 } & $3 \mathrm{~m}$ & $10 \mathrm{~m}$ & $3 \mathrm{~m}$ & $10 \mathrm{~m}$ & $3 \mathrm{~m}$ & $10 \mathrm{~m}$ \\
\hline Suhu $\left({ }^{\circ} \mathrm{C}\right)$ & 25,5 & 25,6 & 25,6 & 25,6 & 25,6 & 25,6 \\
\hline Salinitas $(\%)$ & 34 & 34 & 34 & 35 & 34 & 34 \\
\hline $\mathrm{pH}$ & 7,85 & 7,85 & 7,85 & 7,85 & 7,85 & 7,85 \\
\hline Kecerahan $(\%)$ & 100 & 100 & 100 & 100 & 100 & 100 \\
\hline Kecepatan Arus (m/det) & 0,11 & 0,18 & 0,32 & 0,32 & 0,11 & 0,11 \\
\hline
\end{tabular}

Sumber. Data primer, 2014

Suhu perairan yang di dapat berkisar dari $25,5-25,6^{\circ} \mathrm{C}$, dengan hasil demikian suhu yang di dapat tergolong baik. Menurut DKTNL (2006), suhu paling optimal bagi pertumbuhan karang berkisar antara $23-32^{\circ} \mathrm{C}$. Suhu di bawah $18^{\circ} \mathrm{C}$, dapat menghambat pertumbuhan karang bahkan kematian. Suhu di atas $33^{\circ} \mathrm{C}$ dapat menyebabkan gejala pemutihan.

Salinitas pada setiap stasiun penelitian berkisar dari 34-35 \%o yang mana kondisi ini tergolong baik. Salinitas air laut rata-rata di daerah tropis adalah sekitar $35 \%$, dan binatang karang hidup subur pada kisaran salinitas sekitar 3436 \%o (Supriharyono, 2007). Menurut Dahuri (2003), bahwa umumnya terumbu karang tumbuh dengan baik di wilayah dekat pesisir pada salinitas 30-35\%o.

Keputusan Menteri Kependudukan dan Lingkungan Hidup (KLH No. 2. 1988) dalam Edward (1996), menetapkan bahwa nilai kisaran ambang batas $\mathrm{pH}$ (derajat keasaman) yang baik bagi kehidupan biota laut berkisar diantara 6-9. Kondisi derajat keasaman (ph) pada setiap stasiun pengamatan sebesar 7,85. Isnansetyo dan Kurniastuty (1995), menyatakan bahwa pH berkisar antara 8,09,0 masih dapat mendukung perkembangan fitoplankton.

Kecerahan perairan di setiap stasiun pengamatan memiliki tingkat kecerahan $100 \%$, dikarnakan cahaya matahari menembus sampai kedasar perairan dari tingkat kedalaman 3-10 meter. Keberadaan cahaya matahari sangat penting bagi terumbu karang untuk melakukan proses fotosintesis. Mengingat binatang karang (hermatypic) hidupnya bersimbiosis dengan ganggang (zooxanthellae) yang melakukan fotosintesa. Menurut Suharsono (1996) bahwa pertumbuhan, penutupan dan kecepatan tumbuh karang berkurang secara eksponensial dengan kedalaman. Faktor utama yang mempengaruhi sebaran vertikal adalah intensitas cahaya, oksigen, suhu dan kecerahan.

Kecepatan arus yang didapat pada semua stasiun pengamatan sebesar 0,11-0,32 (m/det). Arus tertinggi terjadi pada stasiun II yang berhadapan langsung dengan laut lepas Samudera Hindia. Arus penting untuk transportasi zat hara, larva, bahan sedimen dan oksigen yang dibutuhkan oleh karang. Selain itu, arus juga berfungsi untuk membersihkan polip karang dari kotoran yang menempel. Nontji (1993), menyatakan bahwa keberadaan arus dan gelombang di perairan sangat penting untuk kelangsungan hidup terumbu karang. Arus diperlukan untuk mendatangkan makanan berupa plankton, di samping itu juga membersihkan diri dari endapan-endapan dan untuk mensuplai oksigen dari laut bebas. 
Menurut Burke et al. (2002), bahwa sedimen dalam kolom air laut dapat sangat mempengaruhi pertumbuhan karang, atau bahkan menyebabkan kematian karang. Kandungan unsur hara yang tinggi dari aliran sungai dapat merangsang pertumbuhan alga yang beracun. Keadaan ini mendorong pertumbuhan alga lain yang tidak saja memanfaatkan energi matahari tetapi juga menghambat kolonisasi larva karang dengan cara menumbuhi substrat yang merupakan tempat penempelan larva karang.

Kualitas perairan pada setiap stasiun penelitian tidak terdapat perbedaan yang begitu jauh namun, kualitas perairan yang terdapat di lokasi penelitian merupakan kualitas perairan yang sangat mendukung untuk kehidupan terumbu karang.

Analisis Indeks Keanekaragaman ( $\left.\mathrm{H}^{\prime}\right)$, Indeks Dominansi (C), Indeks Keseragaman (E) dan Indeks Mortalitas (IM).

Tabel 10. Indeks (H'), (C), (E) dan (IM).

\begin{tabular}{ccccccc}
\hline \multirow{2}{*}{ Indeks } & \multicolumn{7}{c}{ Stasiun } \\
\cline { 2 - 7 } & $3 \mathrm{~m}$ & 10 & $3 \mathrm{~m}$ & $10 \mathrm{~m}$ & $3 \mathrm{~m}$ & $10 \mathrm{~m}$ \\
\cline { 2 - 8 } & 2,25 & 1,87 & 1,95 & 2,02 & 1,5 & 2,07 \\
\hline Keanekaragaman $\mathrm{H}^{\prime}$ & 0,09 & 0,13 & 0,06 & 0,11 & 0,26 & 0,11 \\
\hline Dominansi C & 0,96 & 1,32 & 1,66 & 1,46 & 1,24 & 1 \\
\hline Keseragaman E & 0,96 & 0,08 & 0,49 & 0,63 & 0,82 \\
\hline Mortalitas IM & 0,23 & 0,79 & 0,08 &
\end{tabular}

Sumber. Data primer, 2014

\section{Indeks Keanekaragaman ( $\left.\mathrm{H}^{\prime}\right)$}

Nilai indeks menunjukkan bahwa keanekaragaman karang pada daerah pengamatan memiliki keanekaragaman karang yang sedang. Hal ini sesuai dengan pendapat Suharsono (2008), yang mengemukakan bahwa sebaran karang sebelah barat sumatera merupakan terumbu karang dengan tipe terumbu karang lautan Hindia yang dicirikan dengan keanekaragaman yang relatif rendah. Tersebar mulai dari Pulau Weh di ujung utara dari Pulau Sumatera, sepanjang Pantai Barat Sumatera hingga Pulau Enggano.

\section{Indeks Dominansi (C)}

Indeks dominansi tertinggi pada daerah pengamatan terdapat di stasiun I dengan nilai sebesar 0,1399 dan terendah terdapat pada daerah pengamatan stasiun II yakni sebesar 0,1132 . Pada lokasi penelitian secara umum memiliki nilai yang mendekati 0 , dimana nilai tersebut menyatakan bahwa sebagian besar pada lokasi penelitian tidak ada jenis karang yang mendominasi. Menurut odum (1971), bahwa apabila nilai indeks dominansi mendekati 0 berarti tidak ada jenis yang dominan.

\section{Keseragaman (E)}

Nilai indeks keseragaman menunjukkan bahwa keseragaman karang pada daerah pengamatan dalam kondisi tinggi. Keseragaman tertinggi terdapat pada stasiun 2 dengan nilai indeks sebesar 1,4627, keseragaman terendah terdapat pada stasiun 3 dengan nilai indeks sebesar 1,0086. Nilai indeks keseragaman pada daerah penelitian secara umum memiliki nilai yang melebihi 0,6 dimana nilai tersebut menyatakan bahwa keseragaman populasi karang pada daerah pengamatan tinggi, sehingga dapat dikatakan komunitas stabil (Odum, 1971). 


\section{Indeks Mortalitas}

Nilai indeks mortalitas (IM) Indeks ini memperlihatkan besarnya perubahan karang hidup menjadi mati, terdiri dari komponen penyusunnya adalah tutupan karang hidup, patahan karang (Rubble) dan karang mati (DC). Pada daerah pengamatan kedalaman $3 \mathrm{~m}$ berkisar antara 0,08-0,63. Stasiun I memiliki nilai $0,08 \%$ menunjukkan rasio kematian karang pada daerah pengamatan mendekati nilai 0 , dimana nilai tersebut menyatakan bahwa tingkat kesehatan karang yang baik. Pada kedalaman $10 \mathrm{~m}$ berkisar antara 0,49-0,82\%. Dimana hasil ini ditunjukkan pada stasiun III sebesar $0,82 \%$ dan stasiun I sebesar $0,79 \%$ mendekati angka 1,0 yang berarti menunjukkan adanya perubahan yang cukup besar dari karang hidup menjadi mati, atau kesehatan komunitas karang di stasiun tersebut kurang baik, sedangkan di stasiun II sebesar 0,49\% nilai ini lebih kecil di bandingkan dua stasiun yang lain, namun masih tergolong kondisi yang kurang sehat atau ada perubahan dari karang hidup menjadi mati.

\section{KESIMPULAN DAN SARAN}

\section{Kesimpulan}

Berdasarkan struktur geomorfologi dan proses pembentukannya, terumbu karang yang ada di Perairan Tanjung Gosongseng Pulau Enggano memiliki tipe terumbu karang tepi (Fringing Reef). Tipe-tipe lifeform yang dijumpai di daerah pengamatan di perairan Tanjung Gosongseng Pulau Enggano terdapat 11 jenis bentuk pertumbuhan yakni (ACB), Acropora Digitate (ACD), Acropora Encrusting (ACE), Acropora Submassive (ACS), Acropora Tabulate (ACT), Coral Branching (CB), Coral Massive (CM), Coral Encrusting (CE), Coral Submassive (CS), Coral Foliose (CF), dan Coral Mushroom (CMR).

Persentase tutupan karang rata-rata pada kedalaman $3 \mathrm{~m}$ sebesar $64,44 \%$ termasuk kategori baik, sedangkan rata-rata persentase tutupan terumbu karang pada kedalaman 10 meter kategori sedang. Nilai indeks keanekaragaman $\left(\mathrm{H}^{\prime}\right)$ pada kedalaman 3 dan 10m menunjukkan bahwa nilai kategori keanekaragaman karang yang sedang, nilai indeks keseragaman ( $E$ ) pada kedalaman $3 \mathrm{~m}$ pada daerah pengamatan dalam kondisi keseragaman tinggi, begitu juga dengan kedalaman $10 \mathrm{~m}$. Nilai indeks keseragaman menunjukkan bahwa keseragaman karang pada daerah pengamatan dalam kondisi tinggi, dimana nilai tersebut menyatakan bahwa keseragaman populasi karang pada daerah pengamatan tinggi dan nilai indeks dominansi $(\mathrm{C})$ dengan kedalaman $3 \mathrm{~m}$ tergolong dalam kategori rendah, ini menunjukkan bahwa tidak ada jenis karang yang dominan, begitu juga Pada kedalaman 10m tergolong dalam kategori rendah, ini menunjukkan bahwa tidak ada jenis lifeform karang yang dominan.

Dari hasil pengukuran parameter kualitas air menunjukkan bahwa kualitas perairan Tanjung Gosongseng masih dalam kondisi yang baik untuk pertumbuhan dan perkembangan terumbu karang.

\section{DAFTAR PUSTAKA}

Burke, L., E. Selig, dan M. Spallding. 2002. Terumbu Karang yang Terancam di Asia Tenggara. Ringkasan Untuk Indonesia. Terjemahan dari Reefs at Risk in Southeast Asia. Kerjasama antara WRI, UNEP, WCMC, ICLARM dan ICRAN. 40 hal.

Dartnal, AJ dan M. Jones. 1986. A Manual of Survey Method Living Resources in Costal Areas. The Australian Institute of Marine Science.

Dahuri, R. 2003. Keanekaragaman Hayati Laut. Aset Pembangunan Berkelanjutan Indonesia. Penerbit PT Gramedia Pustaka Utama. Jakarta. 
Direktorat Konservasi dan Taman Nasional Laut. 2006. Pedoman Pelaksanaan Transplantasi Karang. DKP. 36 p.

Edwards, A. J, Clark, C. D. (1996). A review of remote sensing for the assessment and management of tropical coastal resources. Coastal Management 24:1-40.

English, S., Wilkinson, C., and Baker. V. 1997. Survey Manual for Tropical Marine Resources. Asustralian Institut of Marine Sciene. Townsville: 350 p.

Isnansetyo, A . dan Kurniastuti. 1995. Teknik Kultur Fitoplankton dan Zooplankton (Pakan Alami Untuk Pembenihan Organisme Laut). Kanisius. Jogjakarta. 116 hal.

Keputusan Menteri Negara Lingkungan Hidup. 2001. Nomor : 04 Tahun 2001 Tentang Kriteria Baku Kerusakan Terumbu Karang.

Krebs, C. J. 2014. Similarity Coefficients and Cluster Analysis. Chapter 12. Version 5. $530 \mathrm{p}$.

Krebs, C. J. 1985. Experimental Analysis of Distribution and Abudance. Philadelphia: Harper and Publishers. Inc.

Krebs, C. J. 1972. Ecologi : the Experimenthal Analisys of Distribution and Abudance. Harper and Row Publisher. New York. 694 p.

Nontji, A. 1993. Laut Nusantara. Jakarta: Penerbit Djambatan. 368 hal.

Odum, E. P. 1971. Fundamental of Ecology. W.B. Saunders Company. Philadelphia and London. $564 \mathrm{p}$.

Senoaji, G., Riwandi., Cahyadinata, I., Hidayat, M. F., Suminar, R., Magdalena. 2006. Studi Daya Dukung Pemanfaatan dan Pengembangan Kepulauan Enggano. Kerjasama Bapedalda Provinsi Bengkulu dengan Pusat Penelitian Lingkungan Universitas Bengkulu.

Sukarno. 1994. Ekosistem Terumbu Karang dan Masalah Pengelolaanya. P3OLIPI dan Universitas Sam Ratulangi. Manado.

Sukarno, M. Hutomo, K. Moosa dan P. Darsono. 1981. Terumbu Karang Indonesia, Sumberdaya Permasalahan dan Pengelolaannya. Puslitbang Oseanologi LIPI. Jakarta.

Supriharyono. 2007. Konservasi Ekosistem Sumberdaya Hayati di Wilayah Pesisir dan Laut Tropis, Pustaka Pelajar. Yogyakarta.

Suharsono. 2008. Jenis-jenis Karang di Indonesia. Coremap Program LIPI Press : Jakarta. $372 \mathrm{p}$.

Suharsono. 1996. Jenis-Jenis Karang yang Umum Dijumpai di Perairan Indonesia. P2O . LIPI. Jakarta. 103 p.

Suharsono. 1995. Metode penelitian terumbu karang. Kursus Pelatihan Metodologi Penelitian Penentuan Kondisi Terumbu Karang. Jakarta: Pusat Penelitian dan Pengembangan Oseanologi-LIPI.

UNEP. 1993. Monitoring Coral Reefs For Global Change. Regional Seas. Reference Methods For Marine Pollution Studies No. 61. Australian Institute Of Marine Science. 72pp.

WELLS, J.W. 1956. Scleractinia. In : Treatise on invertebrate Palaentology. Part F. Coelentrata (Moore ed). Geol, Soc. Amer. and Kansas Press : 328 478.

Wallace, D. 1998. Coral reefs and their management. www. cep. unep. org. (13 Maret 2003).

Westmacott S., Teleki K., Wells S., dan West J. 2000. Pengelolaan Terumbu Karang Yang Telah Memutih dan Rusak Kritis, Diterjemahkan oleh Jan Hanning Steffen IUCN, Gland, Switzerland and Cambridge, Inggris Information Press, Oxford. 